\title{
PREMIO SOBRE EL MÉDICO MUSULMÁN «MUHAMMAD AL-SHAFRÁ Y SU ÉPOCA»
}

Por

MÍKEL DE EPALZA

La Asociación Muhammad Al-Shafrá surgió como tal de la fecunda inquietud de una serie de personas de Elche y Crevillente que, aglutinados por el Dr. Justo Medrano (médico ilicitano, Catedrático del Departamento de Cirugía de la Universidad de Alicante), se impusieron como objetivo al reivindicar la figura de Muhammad Al-Shafrá, cirujano y farmacólogo originario de estas comarcas del sur alicantino. De este modo, pretenden en última instancia recuperar y divulgar tanto el pasado islámico alicantino, como las personalidades científicas y literarias más notables que fueron sus hitos notables.

Para llegar a la consecución de tales fines, sus actividades han sido variadas y han ido desde la organización de conferencias sobre la figura de AlShafrá, la inauguración de una calle en Elche a él dedicada, o la convocatoria, a finales de 1987, de los Premios "Al-Shafrá", con la finalidad de fomentar, de este modo, la investigación sobre la vida y divulgar la obra de este médico musulmán alicantino del siglo XIV.

Una vez transcurrido el plazo para la presentación de las diversas investigaciones, el 20 de septiembre de 1988 se reunió el Jurado calificador de los varios trabajos que optaban a la consecución de los Premios "Al-Shafrá;; este Jurado estaba compuesto por la Dra. María Jesús Rubiera, Catedrática de Estudios Árabes e Islámicos de la Universidad de Alicante, el Dr. Emilio Balaguer Perigüell, Catedrático de Historia de la Medicina y Decano de la misma Facultad de la Universidad de Alicante, Dr. Rafael Calpena Rico, Profesor de Cirugía de la Universidad de Alicante, don José Riquelme Salar, médico alicantino, Presidente Honorario de la Asociación Muhammad Al-Shafrá, don José Pomares Boix, médico ilicitano y Vicepresidente de la Asociación, don Fernando Candela Polo, médico crevillentino y socio de la Asociación. En esta 
reunión se acordó otorgar el Premio "Villa de Crevillente» al estudio presentado con el título "Muhammad Aš-Šafra Al-Qirbilyanî (m. 1360), el médico y su época», de don Francisco Franco Sánchez (de la Sección de Historia Medieval de la U.N.E.D. de Madrid) y doña Marisol Cabello García (de la Sección de Estudios Árabes e Islámicos de la Universidad de Alicante). Igualmente el Jurado otorgó el Premio "Ciudad de Elche" al trabajo titulado "Muhammad Al-Šafra, la última figura de la cirugía en Al-Andalus», de doña Eloísa Cabero Ruiz (de la Escuela de Estudios Árabes de Granada).

Tras la resolución de los Premios "Muhammad Al-Shafrá", el viernes 30 de septiembre de 1988 tuvo lugar el acto de su entrega en el Salón de Actos del Ayuntamiento de Crevillente (Alicante), estando presentes don Ramón Maŕtín Mateo, Rector de la Universidad de Alicante, Abdeladhar Musly, vicecónsul de Marruecos en Málaga, los alcaldes de Crevillente y Elche, el Dr. don Justo Medrano y la Junta Directiva, miembros de la Asociación Muhammad Al-Shafrá y numerosos público. En este acto, después de unas palabras explicando la trascendencia e importancia del acto por parte del Dr. Justo Medrano, hablaron consecutivamente las personalidades asistentes, explicando el significado de su presencia, y el de las instituciones que representan, como medio de fomento de la recuperación activa del pasado científico e histórico musulmán en unas comarcas en las que todavía queda patente la huella de lo islámico en multitud de aspectos (restos arqueológicos, tradiciones, industria, fiestas, etc.). Después de esto fueron entregados el Premio "Villa de Crevillente» a don Francisco Franco Sánchez y doña Marisol Cabello García y el Premio "Ciudad de Elche» a doña Eloísa Cabero Ruiz. Seguidamente acudieron los asistentes a la inauguración oficial de la placa que denominará la Calle Muhammad Al-Shafrá de Crevillente. El acto concluyó con una cena para personalidades, socios y premiados.

Desde estas líneas abogamos por la multiplicación de este tipo de iniciativas, muy importantes para dirigir la atención de los investigadores hacia una serie de personajes y temas del pasado islámico del Sharq Al-Andalus; de este modo, se irá completando la visión que tenemos de este período de la historia peninsular que trascendió mucho más allá de los ocho siglos que se le adjudican. 